Proc. Indian Acad. Sci. (Chem. Sci.), Vol. 105, No. 6, December 1993, pp. 353-358.

(C) Printed in India.

\title{
Light-induced hydrogen production using waste compounds as sacrifical electron donors
}

\author{
CHRISTIAN KÖNIGSTEIN and RUPERT BAUER* \\ Institute of Physical Chemistry, Technical University Vienna, Getreidemarkt 9/156, A-1060 \\ Vienna, Austria
}

\begin{abstract}
Systems for the conversion and chemical storage of solar energy are usually based on photo-induced electron transfer reactions from an excited sensitizer to an electron acceptor (i.e. an electron relay compound). We have investigated the photo- and electrochemical properties of two novel electron relay compounds: 1,1 "', 1"'-trimethyl $\left[4,2^{\prime}\right.$; $\left.4^{\prime}, 4^{\prime \prime} ; 6^{\prime}, 4^{\prime \prime}\right]$ quaterpyridinium trichloride (1) and $1,1^{\prime}, 1^{\prime \prime}, 1^{\prime \prime \prime}$-tetramethyl $\left[4,2^{\prime} ; 4^{\prime}, 4^{\prime \prime} ; 6^{\prime}, 4^{\prime \prime}\right]$ quaterpyridinium tetrachloride (2). When solutions containing $\mathrm{Ru}(\mathrm{bpy})_{3} \mathrm{Cl}_{2}$ or $\mathrm{Zn}$-porphyrin (as photosensitizer), compound $\underline{1}$ or $\underline{2}$ and EDTA (as sacrificial electron donor) are irradiated by visible light $(i>400 \mathrm{~nm}$ ), only the formation of reduced relay compound 1 occurs. Addition of platinum catalyst to such solutions with compound 1 leads to the formation of hydrogen. Quantum yields are in the range of $5 \%$, calculated for absorbed light. Using other sacrificial electron donors such as alcohols or glucose (or waste compounds like 4-chlorophenol) did not result in hydrogen evolution. However, 1 and 2 are reduced by these sacrificial electron donors in the absence of an additional photosensitizer, when near UV irradiation light $(i .>280 \mathrm{~nm}$ ) is used. Quantum yields for hydrogen production with compound 1 are about $2 \%$, calculated for absorbed light out of GC-measurements from $\mathrm{H}_{2}$ in the gas phase above the irradiated solution. The photo- and electrochemical properties of compounds $\underline{1}$ and $\underline{\underline{2}}$ are discussed.
\end{abstract}

Keywords. Electron transfer; photo-induced hydrogen production; radicals; electron relays; relay sensitizer.

\section{Introduction}

Conversion and chemical storage of solar energy has become more interesting since problems of environmental pollution and greenhouse warming increased. Different approaches have been made for the conversion of light. Besides the production of hydrogen by photovoltaic cells (generating electricity), combined with the electrolysis of water, direct hydrogen production by the direct light driven splitting of water has attracted much attention (Harriman and West 1982; Pelizzetti and Schiavello 1991).

Such systems are based usually on photo-induced charge separation.

$$
\begin{aligned}
& \mathrm{S}+h v \rightarrow \mathrm{S}^{*}, \\
& \mathrm{~S}^{*}+\mathrm{R} \rightarrow \mathrm{S}^{+}+\mathrm{R}^{-}, \\
& \mathrm{A}^{*}+\mathrm{D} \rightarrow \mathrm{A}^{-}+\mathrm{D}^{+} .
\end{aligned}
$$

\footnotetext{
* For correspondence
} 
After excitation (1) a photosensitizer $\left(S^{*}\right)$ releases an electron (2) to an electronaccepting molecule (electron relay, R) or receives an electron (3) from an electron donor (D).

In the presence of a suitable catalyst (e.g. platinum) the reduction of water can be achieved either by the reduced relay radical $\mathrm{R}^{-}$or the reduced sensitizer $\mathrm{A}^{-}$to give $\mathrm{H}_{2}$ :

$$
\mathrm{R}^{-}\left(\mathrm{A}^{-}\right)+\mathrm{H}^{+} \stackrel{\mathrm{Pt}}{\longrightarrow} \mathrm{R}(\mathrm{A})+\frac{1}{2} \mathrm{H}_{2} \text {. }
$$

The reduction of the oxidized sensitizer $\mathrm{S}^{+}$(or the oxidized electron donor $\mathrm{D}^{+}$) can be done either by oxidizing water to oxygen (5) or in the presence of a sacrificial electron donor $\mathrm{D}$. In this case, the oxidation of the electron donor is irreversible in reaction (3) or (6):

$$
\begin{gathered}
\mathrm{S}^{+}\left(\mathrm{D}^{+}\right)+\frac{1}{2} \mathrm{H}_{2} \mathrm{O} \stackrel{\mathrm{RuO}_{2}}{\longrightarrow} \mathrm{S}(\mathrm{D})+\frac{1}{4} \mathrm{O}_{2}+\mathrm{H}^{+}, \\
\mathrm{S}^{+}+\mathrm{D} \rightarrow \mathrm{S}+\mathrm{D}_{\mathrm{ox}} .
\end{gathered}
$$

For practical applications, the use of sacrificial electron donor is of interest, only if it is cheap or a waste product of some other reaction.

The utilization of a (organic) compound as such a donor is strongly limited by the redox potentials of the sensitizer in its ground and excited state(s).

Since the oxidation potentials of widely used sensitizers (e.g. $R u(b p y) 3_{3}^{2+}: E_{0}^{2+13+}=$ $1.27 \mathrm{~V}, E_{0}^{+/ 2+*}=0.8 \mathrm{~V}$ vs. NHE) lie in the region of $+1.5 \mathrm{~V}$, we tried to find other substances with more positive oxidation potentials (in their excited states).

\section{Experimental details}

Compounds $\underline{1}$ and $\underline{2}$ (see figure 1) were prepared according to Eichinger et al (1987) and Bauer and Königstein (1991). Tris (2,2'-bipyridyl) ruthenium(II)chloride. $6 \mathrm{H}_{2} \mathrm{O}$ $\left(=\mathrm{Ru}(\mathrm{bpy})_{3}^{2+}\right.$, Janssen $)$ and methyl viologen $\left(=\mathrm{MV}^{2+}\right.$, Aldrich $)$ were used without further purification.<smiles>[R][n+]1ccc(-c2cc(-c3cc[n+]([R])cc3)[n+]([R])c(-c3cc[n+]([R])cc3)c2)cc1</smiles>

Figure 1. Compounds 1 and $2: \underline{1}$. $\mathrm{R}=-\mathrm{CH}_{3}, \mathrm{R}^{\prime}=-, x=3 ; \underline{2}: \mathrm{R}=\mathrm{R}^{\prime}=-\mathrm{CH}_{3} ; x=4$. 
$H_{2}$-production: Argon-purged solutions [containing $1 \mathrm{ml}$ relay (compound 1 or 2 , $\left.c_{0}=10^{-2} \mathrm{~mol} / \mathrm{l}\right), 0.5 \mathrm{ml}$ acetate buffer $\left(c_{0}=1 \mathrm{~mol} / \mathrm{l}\right), 1 \mathrm{~mol}$ sacrificial electron donor (EDTA, 2-propanol or glucose, $\left.c_{0}=0.1 \mathrm{~mol} / 1\right), 0.3 \mathrm{ml} \mathrm{Pt-catalyst}\left(c_{0}=109 \mathrm{mg} / 1\right.$ prepared according to Bauer and Königstein (1991)) and $0.2 \mathrm{ml}$ water] were irradiated by a $\mathrm{Hg}$ high pressure lamp (photon flux: $I_{0}=(2 \cdot 1 \pm 0.2) \times 10^{16}$ photons s $\mathrm{cm}^{-1}$, calculated from 280 to $580 \mathrm{~nm}$, measured by ferrioxalate actinometry).

Solutions with $\mathrm{Ru}(\mathrm{bpy})_{3}^{2+}$ or proflavine as sensitizer consisting of $0.3 \mathrm{ml}$ sensitizer $\left(c_{0}=5 \times 10^{-3} \mathrm{~mol} / \mathrm{l}\right), 0.6 \mathrm{ml}$ relay (methyl viologen, compound 1 or $2, c_{0}=10^{-2} \mathrm{~mol} / \mathrm{l}$ ), $0.5 \mathrm{ml}$ acetate buffer $\left(c_{0}=1 \mathrm{~mol} / \mathrm{l}\right), 0.5 \mathrm{ml}$ 2-propanol, $0.3 \mathrm{ml}$ platinum catalyst $\left(c_{0}=109 \mathrm{mg} / \mathrm{l}\right)$ and $0.8 \mathrm{ml}$ water were irradiated with visible light $(400 \mathrm{~nm}$ cut-off-filter, $250 \mathrm{~W}$-tungsten halide filament lamp, photon flux: $I_{0}^{400-580 \mathrm{~nm}}=(3.33 \pm 0.05) \times 10^{17}$ photons $\mathrm{s}^{-1} \mathrm{~cm}^{-2}$ ).

The $\mathrm{H}_{2}$-concentration in the gas phase was determined by $\mathrm{GC}$-analysis (Carlo Erba Instruments: GC 6000, with HWD-detector 430, column: $2 \mathrm{~m}$ packed iron steel column, filled with $5 \AA$ molecular sieve, carrier: $\mathrm{N}_{2}(99.999 \%)$ ).

Spectroscopy and fluorescence: All absorption spectra were recorded with a Hitachi 220 spectrophotometer. Fluorescence and excitation spectra were monitored with a Perkin Elmer LS 50 fluorescence spectrophotometer. As solvents, water (twice distilled) and acetonitrile (p.A.) were used. The concentration was $10^{-3} \mathrm{~mol} / \mathrm{l}$, in acetonitrile $\mathrm{BF}_{4}^{-}$was used as counter ion (instead of $\mathrm{Cl}^{-}$).

Cyclovoltammetry: Measurements with compound 1 were reported in Bauer et al (1992); those of 2 were done with a Polarograph VA663 (Metrohm AG) equipped with a Scanner VA E612 and Polarecord E506 reference electrode: $\mathrm{Ag} / \mathrm{AgCl}$; acetonitrile solution (working electrode: hanging mercury drop): supporting electrolyte: ( $0.1 \mathrm{~mol} / 1$ tetrabutyl ammonium perchlorate (TBAP, electrochemical grade), concentration of compound 2: $c=2 \times 10^{-4} \mathrm{~mol} / \mathrm{l}$; scan speed: $v_{\mathrm{s}}=50 \mathrm{mV} / \mathrm{s}-200 \mathrm{mV} / \mathrm{s}$.

\section{Results and discussion}

Out of phosphorescence measurements the 0-0 transition energy of Ru(bpy) ${ }_{3}^{2+}$ is calculated to be $2 \cdot 1 \mathrm{eV}$. With its ground state redox potentials at $E_{0}^{2+/ 3+}=+1 \cdot 27 \mathrm{~V}$ vs. NHE, and $E_{0}^{+/ 2+}=+0.8 \mathrm{~V}$ vs. NHE, those of the excited triplet state are $E_{0}^{2+* / 3+}=$ $0.84 \mathrm{~V}$ and $E_{0}^{+/ 2+*}=0.84 \mathrm{~V}$ (vs. NHE) (Juris et al 1988). So the maximum oxidation power of $\mathrm{Ru}(\mathrm{bpy})_{3}^{3+}$ is $1.27 \mathrm{~V}$ (in the ground state). Only a small number of organic compounds (soluble in water) are known, which can be oxidized at this potential (e.g. EDTA, triethanol amine,...). Alcohols, acids (Kolbe photoreaction!) need a more positive potential for their use as sacrificial electron donor agents.

Light-induced hydrogen production experiments with aqueous solutions of $\mathrm{Ru}(\mathrm{bpy})_{3}^{2+}$ (as photosensitizer), methyl viologen $\left(\mathrm{MV}^{2+}\right.$ ) or compound 1 (as electron relay substance), platinum catalyst, acetate buffer and EDTA gave $\mathrm{H}_{2}$ with quantum yields of 15 and $4 \%$ for $\mathrm{MV}^{2+}$ and 1 , respectively (calculated for absorbed light, Bauer and Königstein 1991, 1993). Using compound 2 instead of $\mathrm{MV}^{2+}$ or $\underline{1}$ as electron relay compound, no $\mathrm{H}_{2}$ could be produced. Since the first reduction potential of $2\left(E_{0}^{(2)}=-1.15 \mathrm{~V}\right.$ vs. NHE, see table 1$)$ is more negative than that of $\mathrm{Ru}(\mathrm{bpy})_{3}^{2+*}$ $\left(E_{0}^{2+* / 3+}=-0.84 \mathrm{~V}\right.$ vs. NHE) no electron transfer can occur from the excited sensitizer to the electron relay according to (2). 
Table 1. Data on compounds 1 and 2 .

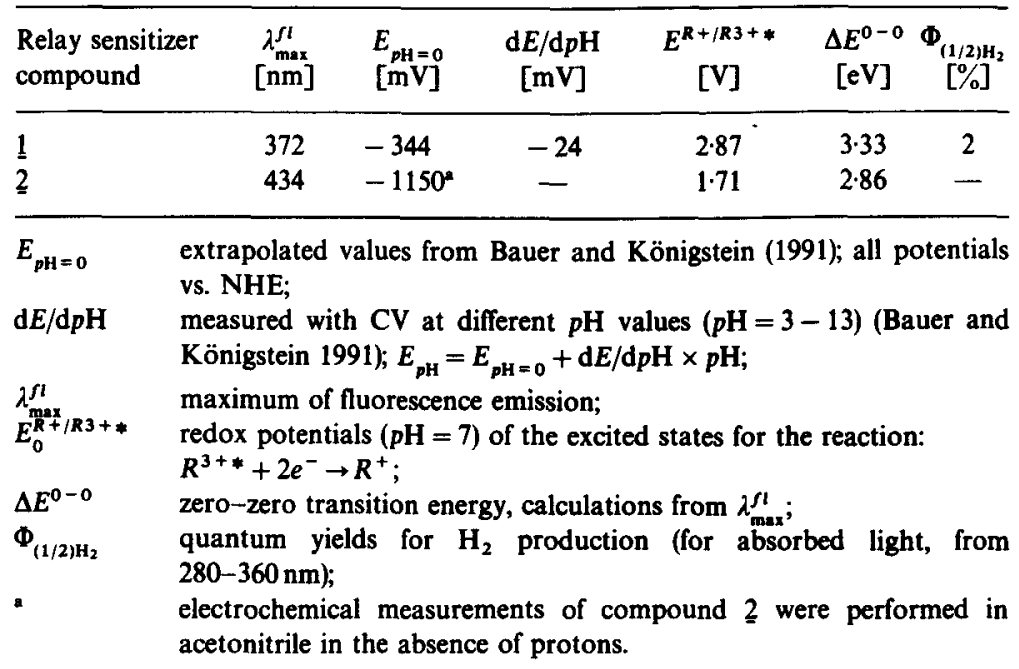

Hydrogen production experiments with other organic sacrificial electron donors (e.g. 2-propanol, glucose, 4-chlorophenol) failed due to unsuitable redox potentials, as described above.

We have shown earlier (Bauer and Königstein 1990, 1991, 1993) that 1,1",1"'-trialkyl $\left[4,2^{\prime} ; 4^{\prime}, 4^{\prime \prime} ; 6^{\prime}, 4^{\prime \prime \prime}\right]$ quaterpyridinium trichlorides can act both as photosensitizers and electron relays when excited by near UV light $(\lambda>280 \mathrm{~nm})$. Excitation maxima in aqueous solutions for compound 1 were found at 300 and $340 \mathrm{~nm}$ (Eichinger et al 1987; Bauer and Königstein 1991).

Fluorescence measurements of aqueous solutions of $\underset{2}{2}\left(c=10^{-3} \mathrm{~mol} / 1\right.$, counter ion: $\mathrm{ClO}_{4}^{-}$) gave emission maxima at 370,569 and $722 \mathrm{~nm}$. Excitation maxima for the luminescence at $370 \mathrm{~nm}$ could be observed at $346 \mathrm{~nm}$ and for the yellow green emission $(569 \mathrm{~nm})$ at 392 and $460 \mathrm{~nm}$ (figure 2).

The results are in good agreement with those obtained for other derivatives in the series of the $1,1^{\prime \prime}, 1^{\prime \prime \prime}$-trialkyl $\left[4,2^{\prime} ; 4^{\prime}, 4^{\prime \prime} ; 6^{\prime}, 4^{\prime \prime \prime}\right]$ quaterpyridinium trichlorides (Eichinger et al 1987; Bauer and Königstein 1991).

Emission properties of both compounds 1 and 2 in acetonitrile were a little different from the results in aqueous solutions, reported above. An additional emission band appears at $427 \mathrm{~nm}(1)$ and $429 \mathrm{~nm}$ (2) with excitation maxima at $367 \mathrm{~nm}(1)$ and $378 \mathrm{~nm}(2)$ (see figure 3).

Electrochemical measurements of $2 \underline{2}$ in acetonitrile gave as a result two reversible reduction steps at $-1 \cdot 15$ and $-1 \cdot 33 . \mathrm{V}$ (vs. NHE). The shift to more negative potentials compared with $\underline{1}$ is attributed to the fourth methyl group in 2 .

Calculating the $0-0$ transition energies out of the fluorescence measurements (Juris et al 1988) of aqueous solutions (see figure 2 and table 1), we found $\Delta E^{0-0}=3.33$ and $3.35 \mathrm{eV}$ for 1 and 2 , respectively. The redox potentials of their excited states are obtained with their ground state redox potentials of $E_{0}^{(1)}=-0.51 \mathrm{~V}$ (vs. NHE, $p \mathrm{H}=7$ ), and $E_{0}^{(2)}=-1.15 \mathrm{~V}$ (vs. NHE) from cyclic voltammetry (CV): $E_{0}^{*}=+2.82$ and $+2.20 \mathrm{~V}$ (vs. NHE) for 1 and 2 , respectively (see table 1). This is much more positive than the potential which can be reached by $\operatorname{Ru}(\mathrm{bpy})_{3}^{2+}$. 


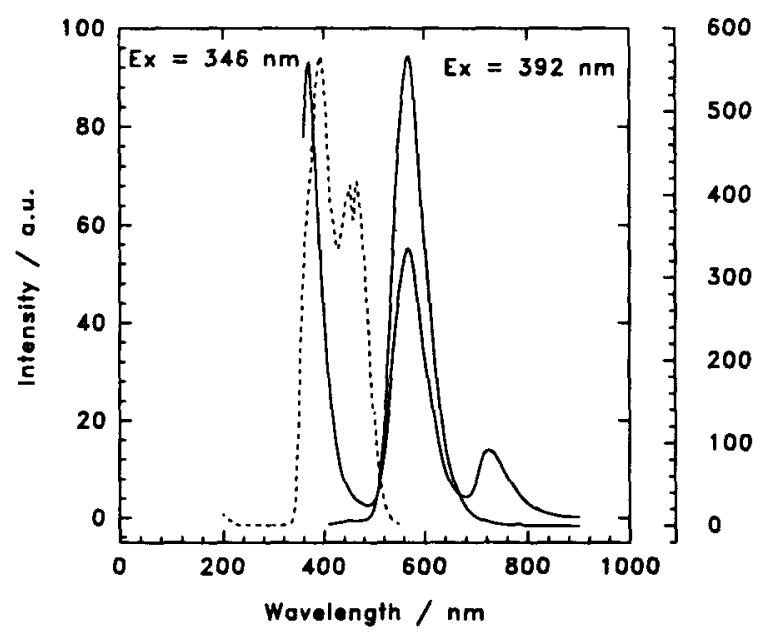

Figure 2. Fluorescence (_- ) and excitation spectra (-- ---) of compounds 2 in water.

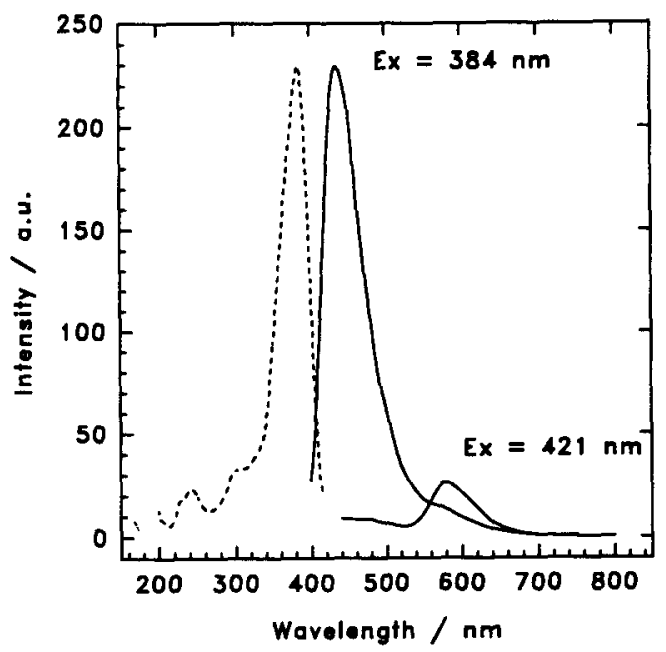

Figure 3. Fluorescence $(-)$ and excitation spectra (----) of compounds 2 acetonitrile.

Excitation of aqueous solutions, containing compound 1 or 2 , phosphate buffer $(p \mathrm{H}=7)$ and a sacrificial electron donor (EDTA, glucose or 2-propanol), with near UV light $(\lambda>280 \mathrm{~nm})$ resulted in the formation of reduced relay molecules and the oxidation of organic compounds. In contrast, $\mathrm{Ru}(\mathrm{bpy})_{3}^{2+}$ was successfully used as photosensitizer only in combination with EDTA as sacrificial electron donor.

In the presence of a platinum catalyst hydrogen could be detected in the gas phase above the solution. The quantum yield was calculated for absorbed light to be: $\Phi_{(1 / 2) \mathrm{H}_{2}}=2 \%$ for compound 1 . However compound 2 was not able to produce $\mathrm{H}_{2}$ under these conditions.

Using waste water containing $100 \mathrm{ppm}$ 4-chlorophenol as sacrificial electron donor agent for photoinduced $\mathrm{H}_{2}$-formation with compound $\underline{1}$ or $\underline{2}$ did not succeed, although thermodynamically allowed. 
A high excess of the electron-donating substance is necessary to obtain sufficiently fast reaction rates. In case of glucose and 2-propanol the initial sacrificial donor concentration was five times the concentration of 1 and 2 , respectively.

\section{Conclusion}

Both compounds 1 and $\underline{2}$ were found to be able to undergo reversible redox processes. The first reduction potentials were determined by cyclic voltammetry $E_{0}=-0.51$ and $-1.15 \mathrm{~V}$ (at $p \mathrm{H}=7$, vs. NHE) for 1 and 2 , respectively. Fluorescence measurements of aqueous solutions showed that both compounds gave blue luminescence emission with its maxima at $372 \mathrm{~nm}(1)$ and at $370 \mathrm{~nm}(2)$, when excited by near UV-light $\left(\lambda^{\mathrm{Ex}}=\sim 340 \mathrm{~nm}\right.$ ). With $0-0$ transition energies (from the emission properties) of 3.33 (1) and $3.35 \mathrm{eV}(2)$, redox potentials of the excited states were calculated: $E^{*(1)}=2.82 \mathrm{~V}$ and $E^{*(2)}=2 \cdot 20 \mathrm{~V}(p \mathrm{H}=7$, vs. NHE). These values are much more positive than the redox potentials of $\mathrm{Ru}(\mathrm{bpy})_{3}^{2+}(0.8 \mathrm{~V}$ excited or $1.27 \mathrm{~V}$ ground state vs. NHE, respectively). Hydrogen production experiments showed that organic compounds in excess can act as sacrificial electron donors with 1 or 2 (as relay-sensitizers).

\section{Acknowledgements}

We wish to thank Professor Dr. Karl Eichinger, of the Institute of Organic Chemistry, for the synthesis of the relay compounds, and for very stimulating discussions. Furthermore, the financial support of the Fonds zur Förderung der Wissenschaftlichen Forschung (Project number 8346) is gratefully acknowledged.

\section{References}

Bauer R, Hofstadler K and Königstein Ch 1992 Proc. Indian Acad. Sci. (Chem. Sci.) 104265

Bauer R and Königstein Ch 1990 in Hydrogen energy progress VIII (eds) T N Veziroglu and P K Takahashi (New York: Pergamon)

Bauer R and Königstein Ch $1991 \mathrm{~J}$. Photochem. Photobiol. A59 61

Bauer R and Königstein Ch 1993 Int. J. Hydrogen Energy 18205

Eichinger K, Nussbaumer P and Vytlacil R 1987 Spectrochim. Acta A43 731

Harriman A and West M A (eds) 1982 Photogeneration of hydrogen (London: Academic Press)

Juris A, Balzani V, Barigeletti F, Campagna S, Belser P and von Zelewsky A 1988 Coord. Chem. Rev. 8485

Pelizzetti E and Schiavello M (eds) 1991 Photochemical conversion of solar energy (Amsterdam: Kluwer) 